\title{
Before the Call
}

\author{
Robert Resta
}

Received: 5 September 2008 / Accepted: 10 September 2008 / Published online: 21 October 2008

(C) National Society of Genetic Counselors, Inc. 2008

\section{Introduction}

Most genetic counselors have had to deliver difficult news more times than they care to recall. Of course, it is always worse for our patients than it is for us. Nonetheless, despite our training and the wisdom that comes with age and experience, it takes its toll on our hearts and souls, and wreaks havoc on our professional and personal insecurities. Such is the steep price we pay for empathy.

I can vividly recall the first time I had to call a patient with difficult news. Afterwards, I took a walk to clear my head. When I came to the corner (Civic Center Drive and Bristol Street, in Santa Ana, California), I could walk no further, paralyzed by my inability to remember if the green light meant I should stop or if I should cross the street. Twenty five years later, I am better at negotiating my way around city streets, but still find the experience no less draining. The following verse captures some of the thoughts that have gone through my head in the moments before I deliver the news.

\section{Before the Call}

I don't want to tell you, I don't want to tell you, I don't want to tell you. And you don't want to know.

Please don't ask me that question, please don't answer my phone call, please don't put yourself to the test.

It's not what you wanted, it's not what you thought, it's not what you hoped for. Things are going to be a mess.
You're going to think you caused it, or maybe you'll feel you deserved it. We all need to blame something, maybe even ourselves.

I didn't sleep last night thinking about you. You won't sleep tonight thinking about me. I wish we both were sleeping, having the same bad dream.

I don't want to tell you, I don't want to tell you, I don't want to tell you. And you don't want to know.

Maybe you'll try to hide the tears, maybe you'll be angry, maybe you'll unnerve me with a scream or even worse a deafening silence.

My insides are all twisted. My brain isn't thinking clear. My hands are shaking. I hope you can't tell.

I'm not the news, just its messenger. I'm almost scared as you are. I'm not sure how to say it. I hope you will forgive me.

I don't want to tell you, I don't want to tell you, I don't want to tell you. And you don't want to know.

You're not going to believe it. You'll say it's a bad mistake or we mixed up your sample. Run it again, run it somewhere else, run away from it all.

I wish I could make it disappear. I only want to help. I've got two kids just like you do.

Maybe you'll move on, or maybe this will drag you down. Maybe you'll try to forget me. But my words will always be caught in the back of your throat.

I don't want to tell you, I don't want to tell you, I don't want to tell you. And you don't want to know.

R. Resta $(\square)$

Hereditary Cancer Clinic, Swedish Medical Center,

1221 Madison, \#1220,

Seattle, WA 98104, USA

e-mail: robert.resta@swedish.org 